\title{
THERMOGRAPHIC INSPECTIONS ON MINI EVAPORATORS TO EVALUATE PERIODIC BOILING HEAT TRANSFER COEFFICIENTS
}

\author{
S. Filippeschi, G. Salvadori \\ Department of Energetics "Lorenzo Poggi" - University of Pisa \\ Via Diotisalvi 2, 56100 Pisa, Italy \\ tel. $+39-050-2217153$ fax $+39-050-2217150$

S.filippeschi@,ing.unipi i g.salva@,ing.unipi.i

\begin{abstract}
A particular two-phase thermosyphon able to operate even against gravity is the Periodic Two-Phase Thermosyphon (PTPT. A PTPT prototype for thermal control miniature applications for electronic equipment cooling has been realised at the Department of Energetics "Lorenzo Poggi" (University of Pisa).

This device is similar to a loop two-phase thermosyphon because it is characterised by two main elements (evaporator and condenser) interconnected by two separated pipes: the vapour line and the liquid line. But a PTPT is characterised by a periodic heat and mass transport inside the loop, so that it operates with periodic difference of temperature and pressures along the loop and a natural circulation even against gravity is realised.

In a such device the evaporator is, therefore, periodically filled and empted of working fluid and the heat transfer regime change periodically during the operation. The critical heat transfer regime that influences very much the global thermal resistance of mini PTPT cooling device is relative to the heat transfer between the hot surface near to chip and the working fluid. In a previous experimental analysis this heat transfer coefficient have been experimentally measured in time during periodic operation with an approximate original method.

One of the main problem of this approximate method has been to analyse the uncertainties in the measurements. For this aim an infrared thermo analysis of the evaporator has been carried out.

This paper presents how the thermographic instruments can be used to evaluate the errors during the periodic boiling heat transfer coefficients measurements In order to understand the experimental method and the themographic analysis carried out a simple description of the experimental apparatus must be made.

The evaporator case of the experimental apparatus is made of aluminium. The electronic components has been simulated by an electric themo-heater that is connected with the evaporator case by a copper dissipator. A PTFE ring thermally disconnects the aluminium case of the evaporator and the upper portion of the copper dissipator. The lower portion of the dissipator is in contact with the environmental air. The lower portion of the copper dissipator can be observed with an infrared thermo-camera as shown in Figure 1. A section of the evaporator and the cylindrical copper dissipator is reported in Figure 2.

The periodic boiling heat transfer coefficient has been experimentally determined by measuring the temperature $\mathrm{T}_{\mathrm{W}}$ of the dissipator with the thermocouple, located $2 \mathrm{~mm}$ under the heat transfer wall, by measuring the temperature $\mathrm{T}_{\mathrm{S}}$ of the vapour inside the evaporator and the heat flux supplied to the dissipator with a frequency of $0.33 \mathrm{~Hz}$.

The transient heat transfer coefficient $\mathrm{h}(\mathrm{t})$ in the evaporator is therefore calculated by the following thermal power balance:
\end{abstract}

$\dot{Q}_{e}=\dot{Q}_{d}(t)-\dot{Q}_{a}(t)-\dot{Q}_{e n v}(t)$

where $\mathrm{Qe}$ is the electric power that is constant on time, $\mathrm{Q}_{\mathrm{a}}(\mathrm{t})$ is the heat stored by the dissipator for each time increment and $Q_{\text {env }}(t)$ is the power loss in the environment. If the power loss through the PTFE ring is considered negligible, $\mathrm{Q}_{\mathrm{env}}(\mathrm{t})$ is equal to the power dissipated in the environment by the lower portion of the copper dissipator.

The thermo-camera allows $\mathrm{T}(\mathrm{r}, \mathrm{z})$ to be measured in the portion of the copper dissipator that has no thermal insulation with a frame frequency of $30 \mathrm{~Hz}$. The surface observed is semi-cylindrical, with a diameter of $0.038 \mathrm{~m}$ and a height of $0.01 \mathrm{~m}$, while the image of the copper dissipator is a rectangular area divided into 1575 pixels of $6 \cdot 10-5 \times 6 \cdot 10-5 \mathrm{~m}$. In this way 25 pixels are in direction $\mathrm{z}$ and 63 pixels in direction $\mathrm{x}$ (where $\mathrm{x}=\mathrm{r} \cdot \cos (\theta)$ ).

If the temperature relative to 20 more external pixels, 10 on the right and 10 on the left, are not taken into account, the temperature can be considered constant for each $\mathrm{z}$ level, with an error lower than $5 \%$ with respect to their mean value. In this way a temperature profile of 14 points in z-direction has been obtained every $0.03 \mathrm{~s}$. The thermal balance of every 14 nodes has been carried out and the heat losses into the environment are so determined in time.

In conclusion, in order to calculate the power $\mathrm{Q}_{\mathrm{d}}$ in time by eq.(2), $\mathrm{Q}_{\mathrm{a}}(\mathrm{t})$ has been evaluate by approximating the function $T(r, z, t)$ in the copper dissipator, with a transient finite difference method. The main results of this analysis are shown in Fig. 3-4. Fig. 3 and Fig. 4 show the evolutions of the heat transfer coefficient $h$, in the case of different values of $\mathrm{VT}$, for $\mathrm{Q}_{\mathrm{e}}=30$ and $40 \mathrm{~W}$, respectively.

In the case of large volumes $\left(>64 \cdot 10^{-6} \mathrm{~m}^{3}\right)$, the maximum heat transfer coefficient is about $11000 \mathrm{~W} / \mathrm{m}^{2} \cdot \mathrm{K}$, while for volumes lower than $3.5 \cdot 10^{-6} \mathrm{~m}^{3}$ the maximum heat transfer coefficient is approximately $5000 \mathrm{~W} / \mathrm{m}^{2} \cdot \mathrm{K}$. The minimum 
heat transfer coefficient is similar for all volumes and it is about $1100 \mathrm{~W} / \mathrm{m}^{2} \cdot \mathrm{K}$. As a result, the heat transfer coefficient decreases down to $20 \%$ of the maximum for small liquid pool volumes $\left(<3 \cdot 10^{-6} \mathrm{~m}^{3}\right)$ or down to $9 \%$ for large liquid pool volumes $\left(>64 \cdot 10^{-6} \mathrm{~m}^{3}\right)$.

The temperature distribution $\mathrm{T}(\mathrm{r}, \mathrm{z}, \mathrm{t})$ determined with the transient finite difference method which supplies the exeriental coefficient shown in figure 3 and 4 has been compared with the temperature distribution measured with a thermal resolution of $0.15 \mathrm{~K}$ by the micro bolometric thermocamera. Figure 5 shows some thermal profile measured by the thermocamera in time. This comparison joined with a detailed analysis o the experimental accuracy of measurements allows the accuracy evaluation of the experimental method.

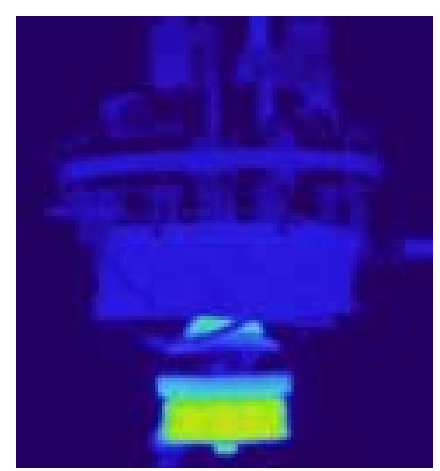

$\mathrm{t}=0 \mathrm{~s}$

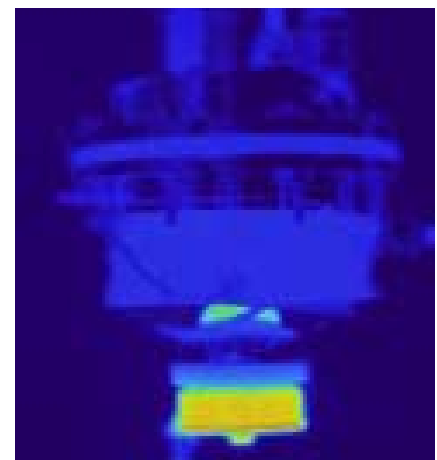

$\mathrm{t}=240 \mathrm{~s}$

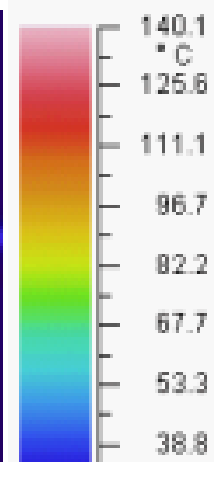

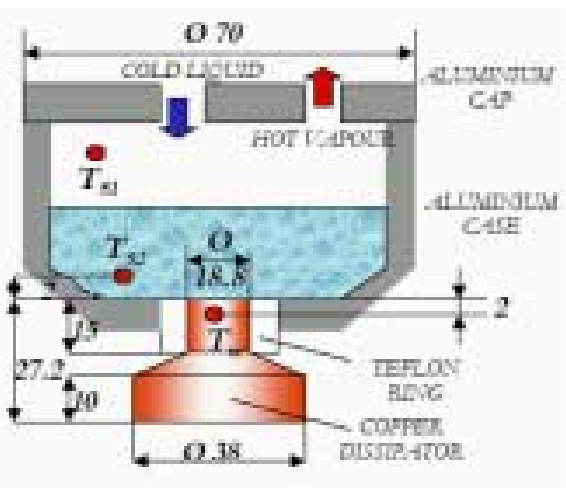

Figure 1- Infrared images of the evaporator at different times and its scheme $\left(\mathrm{q}_{\mathrm{d}}=10.83 \cdot 10^{4} \mathrm{~W} \cdot \mathrm{m}^{2}\right.$ e $\left.\mathrm{V}_{\mathrm{T}}=25 \cdot 10^{-6} \mathrm{~m}^{3}\right)$
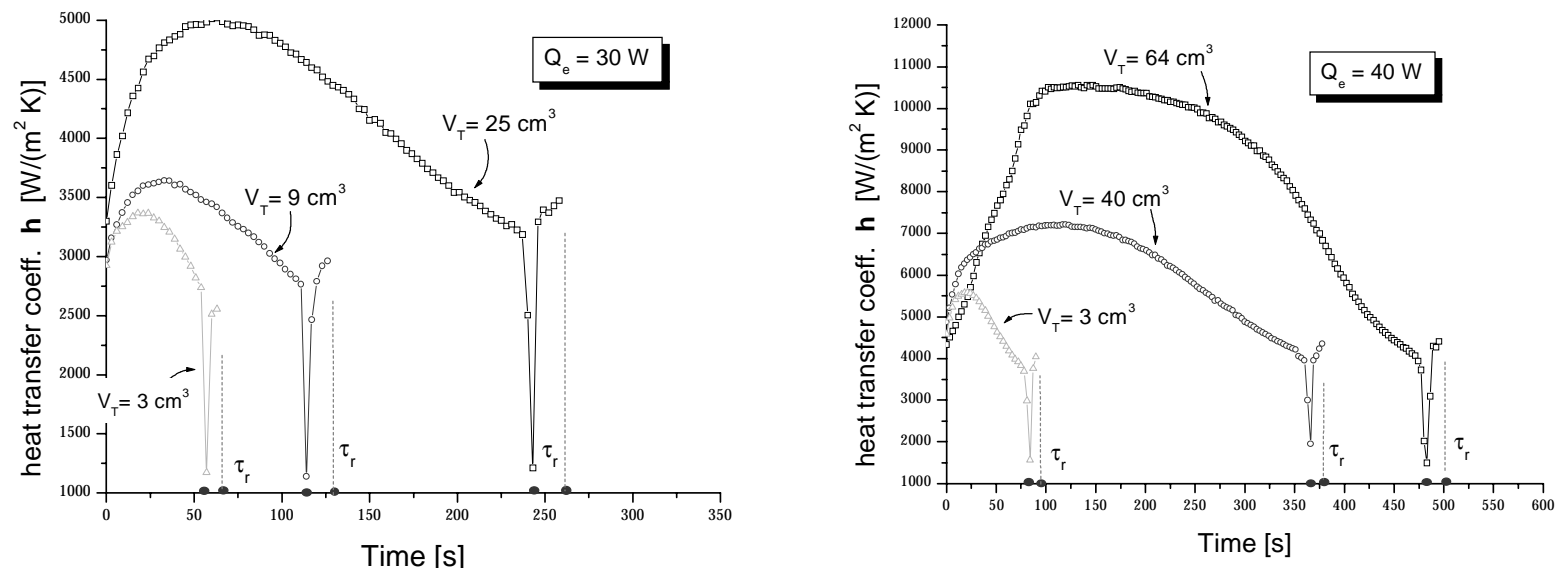

Figure 2 - Evolution of heat transfer coefficient $\mathrm{h}$ for Figure 3 - Evolutions of heat transfer coefficient $\mathrm{h}$ for $\mathrm{Q}_{\mathrm{e}}=30 \mathrm{~W}$ ) $\mathrm{Q}_{\mathrm{e}}=40 \mathrm{~W}$

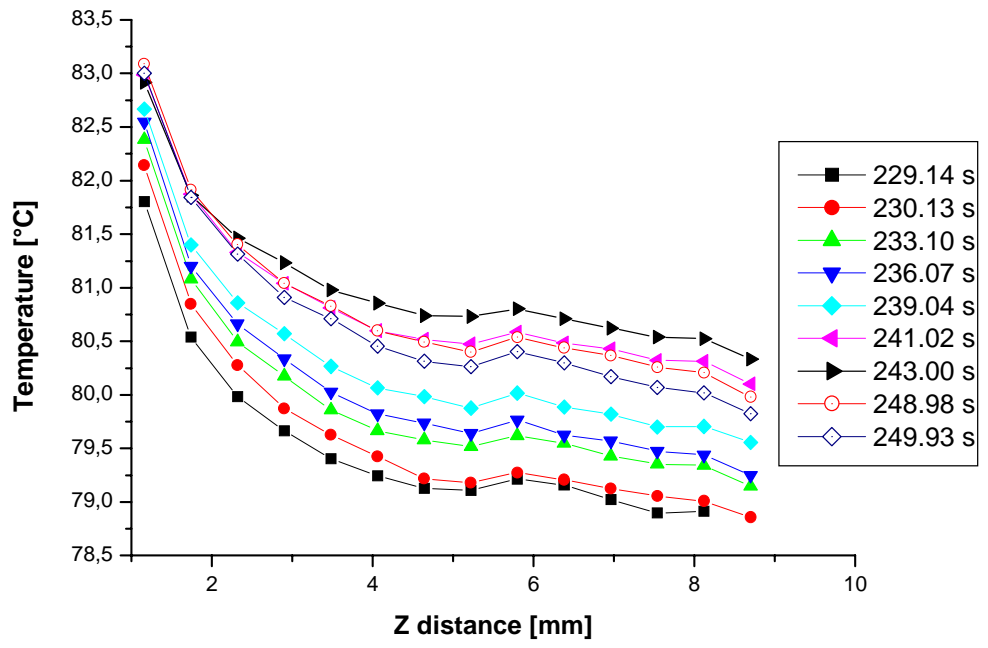

Figure $4-$ Evolutions of the $\mathrm{Ti}(1<\mathrm{i}<10)$ for $\mathrm{Q}_{\mathrm{e}}=30 \mathrm{~W}, \mathrm{~V}_{\mathrm{T}}=25 \cdot 10^{-6} \mathrm{~m}^{3}$ 